\title{
Note on Transliteration and Translation
}

I have used minimal diacritical marks to transliterate Urdu words in this book so as hopefully not to distract the reader. I have specified long vowels with a dash above (as in $\bar{a}$ ) when marking the vowel length helps to clarify the meaning of the word. I have transliterated the Persian izafet as -e, as in the Urdu novel Fasana-e Azad, the Urdu letter che as -ch, and the letter 'ain (when marked) as '. The pen name (takhallus) of Urdu writers has been placed in quotation marks at first mention.

All translations are mine unless otherwise attributed. In my translations I have followed the strategy of trying to maintain the rhetorical effect of the original. If the original Urdu text was of middling quality, as in the zamanab ashob translated in chapter 3, then my translation attempts to convey that. For all satirical works, I have aimed to express the humor of the original. 


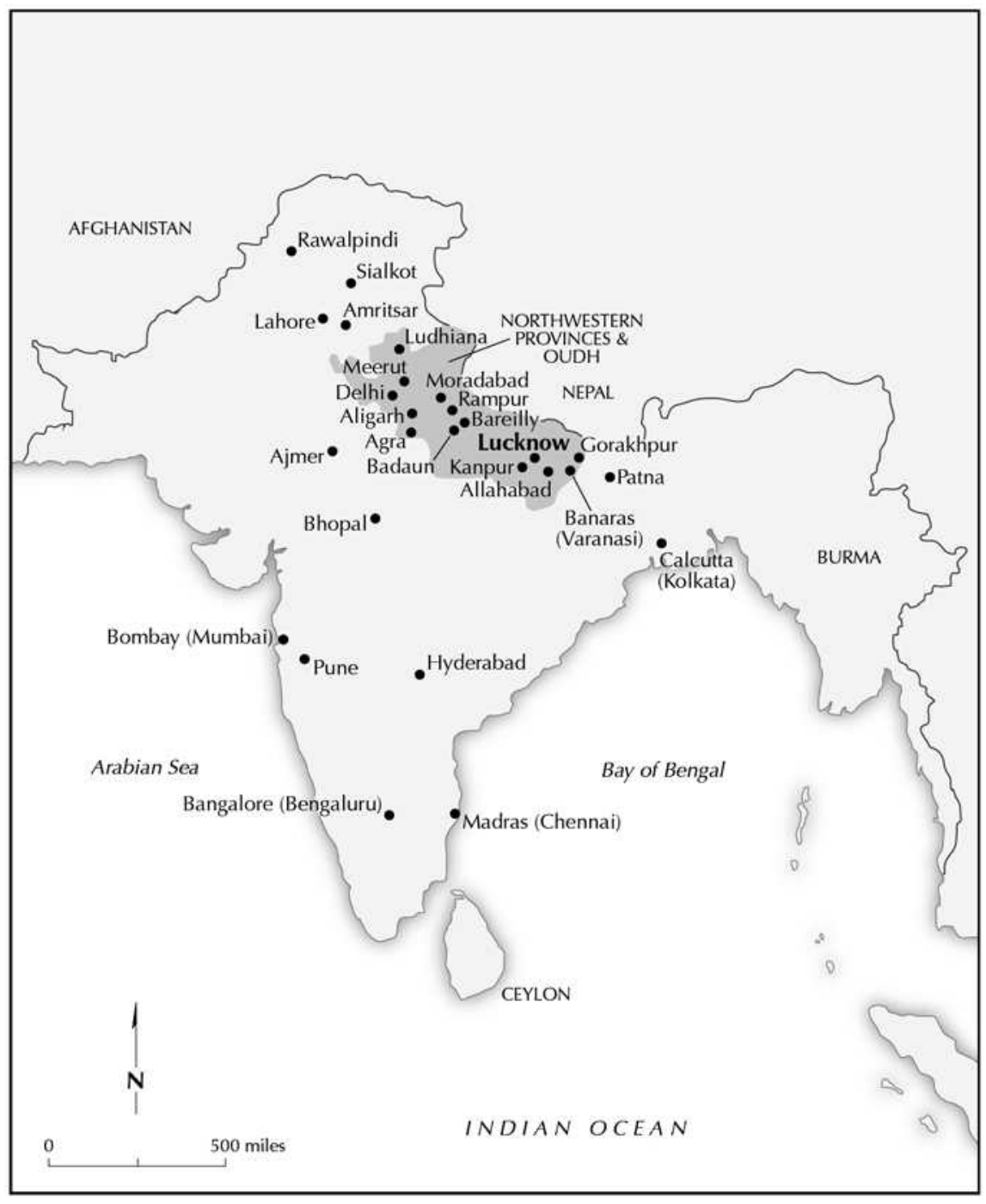

Map 1 Major Urdu Publishing Centers of British India until 1900. 